\title{
The Differences between Iranian Male and Female Students in Using Language Learning Strategies
}

\author{
Zahra Sherafat \\ Department of Language and Literature, Larestan Branch \\ Islamic Azad University, Larestan, Iran \\ E-mail: elnaz.shm@gmail.com \\ Pantea Kabiri \\ Department of Language and Literature, Larestan Branch \\ Islamic Azad University, Larestan, Iran \\ E-mail: kabiripantea@gmail.com \\ Afshin Soori \\ Department of Language and Literature, Larestan Branch \\ Islamic Azad University, Larestan, Iran \\ E-mail: Afshin_soori@yahoo.com
}

Received: 15-02- 2013

doi:10.7575/aiac.ijels.v.2n.2p.58
Accepted: 28-03-2013

Published: $30-04-2014$

\begin{abstract}
The current study aimed at investigating the differences between male and female Iranian students in using different learning strategies. The participants of the study included 60 Iranian EFL students (30 male and 30 female) in Islamic Azad University in Larestan branch. The results of this study revealed that the frequency of using different learning strategies were different for the students. In this case, memory strategies were the most frequent and cognitive strategies were the least frequent strategies used by the students. However, there were significant differences between male and female students in the use of different learning strategies. In fact, female students were the ones who were using language learning strategies more often.
\end{abstract}

Keywords: learning strategies, gender, English learning

\section{Introduction}

For several decades learning strategies have been considered as interesting issues in second or foreign language learning. In fact, foreign language learners take advantage of numerous strategies to master the foreign language learning (O'Malley and Chamot, 1990, Gardner and MacIntyre, 1993). To Oxford (1990) learning strategies are a set of actions by learners that make learning easier, faster, and more enjoyable. Learning strategies as O'Malley and Chamot (1990) state are ways of processing information which can increase comprehension and learning. In the process of second language acquisition, these are learning strategies that can assist learners mastering the language forms and functions (Rubin, 1981). However, they can influence on language achievement (Shmais, 2003; Wharton, 2000; Yu, 2003). It seems that successful learners can use more strategies than less successful learners. Language learners take advantage of these strategies intentionally to make the learning effective.

Learning strategies can make differences among foreign language learners. The main focus of previous studies was on the role of learning strategies in language acquisition, and their connections to learning styles, motivation, anxiety and some other factors (Bozinovic and Sindik, 2011). There are a range of terms in relation to learning strategies like techniques, tactics, study skills, and cognitive abilities. Stern (1986) refers to the differences between learning strategies and techniques as specific procedures. Learning strategies as Chamot (1987) states are techniques, approaches or deliberate actions that recall linguistic and content area information. Learning strategies are considered as behaviors learners engage in during learning which can influence the learners' encoding process. Oxford (1990) refers to strategies as behaviors that can make learning easier, faster, enjoyable, and more transferable to new situations. Other researchers like Ellis (1995) believe that strategies are mental activities or behaviors that take place in a particular phase of learning.

Earlier studies on learning strategies included strategies used by successful foreign language learners. It seems that successful language learners take advantage of a series of strategies in the process of language learning (Gimeno, 2002; Grenfell, 2004). Strategy instruction is an important issue that has been highlighted in many different studies. To Wenden (1998) when the learners are aware of the value and purpose of strategy training, it can be more effective. 
Some strategies are explicit, and these explicit strategy instructions will raise the awareness of the learners about "strategies they already use are set of new, adequate and effective strategies within a particular language context" (Bozinovic and Sindik, 2011, p. 7). Sometimes the strategy instruction is aimed to encourage learners' autonomy to select their own strategies spontaneously without any teacher's intervention. Learners themselves should evaluate the effectiveness of strategy they use and develop problem-solving skills (Bozinovic and Sindik, 2011). Although teachers are able to teach strategies, learners can individually select and implement the useful strategies. S/he can select the best strategy and focuses on how to learn and not what to learn.

Some researchers (Chamot and Kupper, 1989) refer to relationship between different learning strategies used by the learners and the learning achievement. Unlike less successful learners, successful language learners use some effective learning strategies (Hosenfeld, 1977). To Vann and Abraham (1990), successful language learners can mix appropriate strategies for doing a task. In fact, successful language learners mix cognitive strategies and metacognitive strategies (Oxford and Crookall, 1989). In contrast, less successful learners take advantage of a few numbers of strategies (Nyikos, 1987 as cited in Gimeno, 2002). Nyikos (1987) believes that the majority of less successful learners are not aware of the strategies they use. A less successful learner can be a successful learner provided that $\mathrm{s} / \mathrm{he}$ is able to combine learning strategies and make use of them in a correct way (Lavine and Oxford, 1990). In his study, Stern (1975) considered learning strategies used by successful learners. To Stern, some factors like personal learning style and the encouragement of positive learning strategies are significantly important.

\title{
1.1 The Classification of Learning Strategies
}

Oxford (1990) classified learning strategies into direct and indirect strategies. Direct strategies included cognitive and comparison strategies, and memory. The indirect strategies contain metacognitive, affective, and social strategies. Target language is not directly under the influence of indirect strategies, but they have an important role in language learning. Some researchers criticized the classification provided by Oxford. They believe that this classification is not based on factor analysis and achievements of cognitive science (Bozinovic and Sindik, 2011). Moreover, it seems that there is no significant difference between the strategies of language use and the strategies of language learning. To Dörnyei, 2005, compensation strategies are not among language learning strategies. Communication strategies are other types of strategies that are difficult to be separated from memory strategies and memory strategies themselves constitute a subclass of cognitive strategies. As Dörnyei (2005) states, memory strategies are connected with shallow processing, but cognitive strategies are connected with deep processing.

There is another classification for learning strategies by O'Malley and Chamot (1990) which makes a difference between cognitive, metacognitive and social/affective strategies. In this classification, the cognitive strategies are connected with Oxford's memory strategies and social/affective strategies are connected with Oxford's social, affective and communication strategy categories. Dörnyei (2005) suggests a typology of strategies which contains four components

\begin{abstract}
"like cognitive strategies which include a specific manipulation or transformation of material to be learned, i.e.language input, such as repetition of material, summarizing of information, use of mnemonics, etc.; metacognitive strategies (2) as higher-order strategies which comprise analysis, monitoring, evaluation, planning and organizing one's own learning process; social strategies (3) which include interaction with other learners, the goal of which is to increase the amount of L2 communication and practice in a foreign language (initiating interaction with native speakers, cooperation with peers); affective strategies (4) which include the user's control over one's own emotions and experiences that reflect the user's subjective involvement in the learning process" (Bozinovic and Sindik, 2011, p.9).
\end{abstract}

According to O'Malley and Chamot (1990), some researchers do not consider any clear boundary between cognitive and metacognitive strategies. Most of them believe that metacognitive strategies are executive and cognitive strategies are operational strategies. Metacognitive strategies contain "thinking about the learning process, planning of learning, observation of understanding or production, and self-evaluation of learning" (Bozinovic and Sindik, 2011, p.10). However, cognitive strategies are related to direct and specific tasks in the learning process. The importance of metacognitive has been discussed by Cohen and Dörnyei (2002) which defined them as processes which were used by learners consciously to check their own learning. In fact, metacognitive strategies let the learners control their own cognition. In this case, the learners are able to plan their activities, check, and evaluate them. O'Malley and Chamot(1990) believe that learners should have the metacognitive approach and they should know how to apply it. Nevertheless, they may not have a real goal and direction, or any planning for their own learning.

\subsection{The Differences between Males and Females in Using Learning Strategies}

There are a large number of studies which investigated the impact of the gender on the use of learning strategy. The results of some studies (e.g. Lan \& Oxford, 2003; Lee \&Oh, 2001; Oxford \& Ehrman, 1995; in Lee and Oxford, 2008) revealed that men used learning strategies less than women. Oxford et al. (2008) found out that gender had an important impact on the strategy use. The findings of some other studies showed that women could use cognitive and social strategies more frequently. To Oxford and Nyikos (1989) gender plays a significant role in the selection of strategies. The findings of this study also indicated that in comparison with men, women tend to use all types of strategies. These findings were in line with the research conducted by Ehrman and Oxford (1989) on adult learners. The previous studies showed that learning strategies, authentic strategies, communication strategies, and self-direction have been used by female respondents. 
Zimmerman and Martinez-Pons (1990) found that metacognitive strategies such as planning and monitoring strategies were used more by females. Some studies (Dadour \& Robbins, 1996; Oh, 1996; Park, 1999) revealed that there was no clear connection between strategy use and gender. To Kaylani (1996), males were different from females in the use of strategy. She found that females used memory, comparison and affective strategies more than males. In this case, the relationship between gender and language was established. Dongyue (2004) was another researcher who carried out a research on the relationship between language proficiency, gender and strategy use. The findings revealed that genders were different in memory, affective, and overall strategy use. These studies also showed that "females are better at managing and controlling their emotions than their male counterparts" (Bozinovic and Sindik, 2011, p.12). More findings showed that females were better at managing and controlling emotions than males. Some variables like ethnic background, cultural background, and language learning environment were variables which could differentiate between men and women.

\section{Objective of the study}

Regarding the previous studies conducted by the other researchers, this study aimed at considering gender differences in using different learning strategies. The researcher was also interested in differences in the frequency of learning strategy use. Regarding the purpose of the study, the research question of the current study was as follows:

Is there any significant difference between male and female students in using learning strategies?

\section{Methodology}

\subsection{Participants}

The participants of the current study were 60 Iranian EFL students in Islamic Azad University, Larestan branch. They were 30 male and 30 female students. They were chosen based on the result of an Oxford Placement Test. They were supposed to answer questions provided in their questionnaires.

\subsection{Instrument}

A learning strategy questionnaire was considered as an instrument to examine the learning strategy use. The questionnaire was taken from Bozinovic and Sindik, (2011) and some of the items has been adopted from Rebecca Oxford's SILL questionnaire (Strategy Inventory for Language Learning, 1990). The questionnaire includesd 55 items that was corresponding to individual foreign language learning strategies. The questionnaire was a three-point scale. It also provided some demographic information about the participants like gender, age, and language learning level. The reliability of the questionnaire had been found by Kevin Chi-Him Tam as .93 to .98

\subsection{Data collection and analysis}

To collect the data, the researcher took part in English classes in Islamic Azad University and asked the selected male and female students to answer the questionnaire. The data collected through a questionnaire were put into SPSS 16. Data analysis was performed using descriptive statistics. A one-way ANOVA was run to recognize whether there was a significant difference between gender and different learning strategies

\section{Results}

Descriptive analysis of learning strategies was done to check the frequency of individual strategy use. As indicated in Table 1, memory strategies and cognitive strategies were the most frequent and least frequent strategies in order used by the students.

Table1. Descriptive statistics for learning strategies

\begin{tabular}{lllll}
\hline Learning strategies & Mean & Standard Deviation & Min & Max \\
\hline Memory strategies & 3.472 & .2567 & 1.43 & 2.89 \\
Social strategies & 2.361 & .3345 & 1.24 & 3.12 \\
Metacognitive strategies & 1.785 & .3798 & .98 & 2.87 \\
Cognitive strategies & 1.478 & .3968 & 1.32 & 2.67 \\
\hline
\end{tabular}

Table 2 indicates that Iranian male and female students used learning strategies with different frequencies. According to this table, female learners used different learning strategies more than male learners. The females were different from males in use of social strategies. In other words, the female students used social strategies more than other strategies. While for male students the social strategies ranked the fourth strategies. Male learners were medium users of learning strategies and female learners were high users for social and cognitive strategies and medium users for memory, and metacognitive strategies. 
Table2. The difference between males and females in using different strategies

\begin{tabular}{llllll}
\hline & $\begin{array}{l}\text { Mean score for } \\
\text { males }\end{array}$ & $\begin{array}{l}\text { Ranking of } \\
\text { strategies for } \\
\text { males }\end{array}$ & $\begin{array}{l}\text { Mean score for } \\
\text { females }\end{array}$ & $\begin{array}{l}\text { Ranking of } \\
\text { strategies for } \\
\text { females }\end{array}$ & P-value \\
\hline Memory strategies & 2.53 & 4 & 2.88 & 4 & 0.000 \\
$\begin{array}{l}\text { Social strategies } \\
\begin{array}{l}\text { Metacognitive } \\
\text { strategies }\end{array}\end{array}$ & 2.94 & 3 & 3.65 & 1 & 0.000 \\
$\begin{array}{l}\text { Cognitive } \\
\text { strategies }\end{array}$ & 3.95 & 2 & 3.52 & 3 & 0.008 \\
\hline
\end{tabular}

To recognize whether there was a significant difference between gender and different learning strategies, a one-way ANOVA was run to analyze the data. The results of one-way ANOVA revealed that there was a significant difference between gender and different learning strategies. The finding of this study was in line with the findings of the previous studies such as Cohen and Dörnyei (2002).

However, findings of the current study were different from Green and Oxford's (1995) findings who found a significant difference in metacognitive, social, and memory, but no significant difference in cognitive strategies.

It might be assumed that cultural difference or education systems are two important factors for the difference in the findings of the current study and those in previous studies. Education system in Iran may be a reason for this variation among male and female learners for using different strategies. For example, in some countries like United States the emphasis is on the students' interest in learning, and the system is student-oriented, while in countries like Iran that English is considered as a foreign language, the education system is examination-oriented, and getting good marks is the final aim for any student.

\section{Discussion}

Similar to previous studies (Green \& Oxford 1995; Wharton 2000), the findings of the current study revealed that there was a significant difference between male and female students in using different learning strategies. Green and Oxford (1995) pointed out that "gender differences trends in strategies use are quite pronounced within and across cultures, and this means women and men are using different approaches to language learning" (291). Female learners used different learning strategies more than male learners. A significant difference was seen for all learning strategies. The findings also indicated that female learners used social strategies more than male learners. This result was in line with the findings of a study by Yang (1992) who asserted that males and females are different in the use of socially-based strategies. The result of the study by Politzer (1983) revealed that female English language learners in college used social strategies more frequently than male English language learners. The findings of the current study imply that male learners are reluctant to ask for help from other learners. So, they take a proactive role in communication (Chi-Him Tam, 2013). To Tannen (1990), males likes to be independent, while females like more cooperation and intimacy. Seeking for help is a sense of inferiority and humble, which hampers the sense of cooperation with other learners in English language classes.

\section{Conclusion}

The aim of the current study was to investigate the difference between male and female students in using different learning strategies. There was an initial hypothesis that different genders used different learning strategies that was confirmed by the result of this study. The results revealed that there was a statistically significant differences in the frequency of learning strategies by both male and female students. The most frequent strategies by students were memory strategies and cognitive strategies were least frequent strategies. Moreover, the study showed that all learning strategies were used more frequently by female students than male students. Since the results of this study showed the weaknesses of students to use some learning strategies, teachers are suggested to teach students how to use different learning strategies successfully.

\section{References}

Chamot, A. and Kupper, L. (1989), Learning Strategies in Foreign language Instruction. Foreign language Annals, 22, 13-24.

Dongyue, L. (2004), EFL Proficiency, Gender and Language Learning Strategy Use

Among a Group of Chinese Technological Institute English Majors. Arecls E-Journal, 1 (A5).

Dörnyei, Z. (2005), The Psychology of the Language Learner. Individual differences in Second Language Acquisition. London: Lawrence Erlbaum Associates, Inc.

Ellis, R. (1995), The study of Second Language Acquisition. Oxford: Oxford University Press. 
Ehrman, M. and Oxford, R. (1989), Effects of sex differences, career choice, and psychological type on adult language learning strategies. The Modern Language Journal 73 (1), 1 - 13.

Gardner, R.C. and MacIntyre, P.D. (1993), A student's contribution to second-language learning. Part II: Affective Variables. Language Teaching, 26, 1-11.

Gimeno, V. V. (2002), Grammar Learning through Strategy Training: A Clasroom Study on Learning Conditionals through Metacognitive and Cognitive Strategy Training, doctoral dissertation, https://proxy.knjiznice.ffzg.hr Accessed October, 2009.

Hosenfeld, C. (1977), A Preliminary Investigation of the Reading Strategies of Successful and Unseccessful Second Language Learners. System, 4, 116-123.

Kaylani, C. (1996), The influence of gender and motivation of EFL learning strategy use in Jordan. In R. Oxford, (ed.) Language Learning Strategies Around the World: Cross-cultural perspectives (pp. 75-88). Honololu: University of Hawai'i: Second Language Teaching and Curriculum Center.

O'Malley, J.M. and Chamot, A.U. (1990), Learning Strategies in Second Language Acquisition. New York: Cambridge University Press.

Oxford, L.R. (1990), Language Learning Strategies: What Every Teacher Should Know. Boston: Heinle and Heinle Publishers.

Oxford, R.L. and Crookall, D. (1989), Research on Language Learning Strategies: Methods, Findings and Instructional Issues. Modern Language Journal, 73, 404-419.

Politzer, Robert L. 1983. An exploratory study of self reported language learning behaviours and their relation to achievement. Studies in Second Language Acquisition 6.1: 54-68.

Rubin, J. (1981), „The study of cognitive processes in Second Language Acquistion", Applied Linguistics, 2, 117-131.

Shmais, W.A. (2003), Language learning strategy use in Palestine. TESL-EJ 7(2), A-3. Stern, H.H. (1986), Fundamental Concepts of language Teaching. Oxford: Oxford University Press.

Tannen, Deborah. 1990. You Just Don't Understand: Women and Men in Conversation. New York, NY: Ballantine Books.

Vann, R. and Abraham, R. (1990), Strategies of Unsuccessful Language Learners. Paper presented at the 24th Annual TESOL Convention. San Francisco, CA. March, 199909.

Wharton, G. (2000), Language learning strategy use of bilingual foreign language learners in Singapore. Language Learning, 50 (2), 203-244.

Yang, Nae-Dong. 1992. Second language learner's beliefs about language learning and their use of language learning strategies: A study of college students of English in Taiwan (Unpublished doctoral dissertation). Austin, TX: The University of Texas.

Yu, L. (2003), Learning strategies and their relationship to listening comprehension. A report on Non-English majors in a medical university in China. Teaching English in China, 26 (4), 3-11. 